\title{
Letter to the Editor: Validity of the results of a perioperative protocol to reduce shunt infections
}

\author{
Varun R. Kshettry
}

Received: 18 December 2013 / Accepted: 18 January 2014 / Published online: 4 February 2014

(C) Springer-Verlag Wien 2014

Dear Editor,

I read with interest the article by Hommelstad et al. demonstrating a reduction in shunt infection rates, primarily in children below 1 year of age, after implementation of a perioperative protocol [1]. I would like to highlight a potential limitation in the study methodology that could significantly impact the interpretation of the efficacy of their perioperative protocol. Although not listed as part of the protocol, the authors state that in the post-protocol cohort, antibiotic-impregnated shunt (AIS) catheters were used at the discretion of the treating physician. AIS catheters were used in 200 (21.6\%) of the procedures post-protocol compared to zero in the pre-protocol cohort. In patients less than 1 year in age, $52 \%$ received an AIS catheter post-protocol. AIS catheters were selectively used in patients considered to be at high risk for shunt infection. The authors state that there was no significant difference in infection rate between the 200 AIS catheter operations compared to the 727 non-AIS catheter operations $(\mathrm{p}=0.935)$. In patients less than 1 year of age, there was also no statistically significant difference in infection rate between AIS and non-AIS operations, although with a lower p-value (0.179). The authors interpret this finding to indicate that AIS catheters did not contribute significantly to the reduction in shunt infection in the post-protocol cohort. However, the selection bias in this statistical comparison must not be overlooked. One would expect a significantly higher infection rate in the highrisk population, so the finding that a high-risk population receiving AIS catheters had a similar infection rate to a lowrisk population receiving non-AIS catheters should be interpreted as possible evidence that AIS catheters resulted in a reduction of shunt infection. In the pediatric population, a recent meta-analysis revealed that shunt infection occurred in $11.2 \%$ of non-AIS versus $5.0 \%$ of AIS catheter procedures [2]. In the trial by Hommelstad et al., the use of AIS catheters in patients deemed to be at high risk should be considered as part of the new protocol introduced by the authors. As a result, the true effect of the perioperative protocol in the absence of AIS catheters remains uncertain.

\section{References}

1. Hommelstad J, Madso A, Eide PK (2013) Significant reduction of shunt infection rate in children below 1 year of age after implementation of a perioperative protocol. Acta Neurochir (Wien) 155:523-531

2. Parker SL, Anderson WN, Lilienfeld S, Megerian JT, McGirt MJ (2011) Cerebrospinal shunt infection in patients receiving antibioticimpregnated versus standard shunts. J Neurosurg Pediatr 8:259-265

\footnotetext{
V. R. Kshettry $(\bowtie)$

Department of Neurosurgery, Neurological Institute, Cleveland Clinic, 9500 Euclid Ave, S40, Cleveland, OH 44195, USA

e-mail: kshettv@ccf.org
} 